\title{
Increased transplant-related morbidity and mortality in CMV-seropositive patients despite highly effective prevention of CMV disease after allogeneic T-cell-depleted stem cell transplantation
}

Annoek E. C. Broers, Ron van der Holt, Joost W. J. van Esser, Jan-Willem Gratama, Sonja Henzen-Logmans, Vibeke Kuenen-Boumeester, Bob Löwenberg, and Jan J. Cornelissen

\begin{abstract}
We evaluated the efficacy, toxicity, and outcome of preemptive ganciclovir (GCV) therapy in 80 cytomegalovirus (CMV)seropositive patients allografted between 1991 and 1996 and compared their outcome to 35 seronegative patients allografted during the same period. Both cohorts were comparable with respect to diagnosis and distribution of high- versus standard-risk patients. All patients received a stem cell graft from an HLAidentical sibling donor, and grafts were partially depleted of $\mathrm{T}$ cells in 109 patients. Patients were monitored for CMV antigenemia by leukocyte expression of the CMV-pp65 antigen. Fifty-two periods
\end{abstract}

of CMV reactivation occurring in 30 patients were treated preemptively with GCV. A favorable response was observed in 48 of 50 periods, and only 2 patients developed CMV disease: 1 with esophagitis and 1 with pneumonia. Ten of 30 treated patients developed GCV-related neutropenia (less than $0.5 \times 10^{9} / L$ ), which was associated with a high bilirubin at the start of GCV therapy. Overall survival at 5 years was $64 \%$ in the CMV-seronegative cohort and $40 \%$ in the CMV-seropositive cohort $(P=.01)$. Increased treatmentrelated mortality accounted for inferior survival. CMV seropositivity proved an independent risk factor for developing acute graft-versus-host disease, and acute graft-versus-host disease predicted for higher treatment-related mortality and worse overall survival in a timedependent analysis. We conclude that, although CMV disease can effectively be prevented by preemptive GCV therapy, CMV seropositivity remains a strong adverse risk factor for survival following partial T-cell-depleted allogeneic stem cell transplantation. (Blood. 2000; 95:22402245)

$\odot 2000$ by The American Society of Hematology

\section{Introduction}

Cytomegalovirus (CMV) infection is an important cause of morbidity and mortality in recipients of allogeneic stem cell transplantation (SCT). ${ }^{1,2} \mathrm{CMV}$ can cause primary infections or may be reactivated in $\mathrm{CMV}$-seropositive recipients and $\mathrm{CMV}$-seronegative recipients receiving a graft from a seropositive donor. ${ }^{3}$ If untreated, CMV pneumonia may develop in up to $50 \%$ of bone marrow transplant (BMT) recipients showing virus reactivation. ${ }^{1}$ The mortality of CMV pneumonia has remained high despite the use of $\mathrm{CMV}$-specific immunoglobulins and potent antiviral agents such as ganciclovir (GCV). ${ }^{4-6}$ Therefore, preventive measures are considered of utmost importance and have received a great deal of interest. It has been shown that prophylaxis with GCV effectively prevents CMV disease following allogeneic transplantation. ${ }^{7-9}$ However, GCV prophylaxis administered for a prolonged period after BMT has been complicated by severe neutropenia, which itself is associated with an increased risk of opportunistic infections and enhanced treatment-related mortality (TRM). ${ }^{7-9}$ Alternatively, GCV may also be administered as preemptive therapy based on the identification of CMV in blood or bronchoalveolar lavage (BAL). Randomized and retrospective studies have shown a significant reduction of CMV disease and enhanced survival in CMVseropositive donor-recipient pairs receiving GCV as preemptive therapy while avoiding severe neutropenia. ${ }^{10-16}$ However, it is still unclear how the outcome of HLA-matched sibling BMT in CMV-seropositive patients receiving GCV preemptively compares to the outcome of BMT in seronegative patients.

We set out to evaluate the efficacy, toxicity, and possible risk factors of the preemptive use of GCV in CMV-seropositive patients, initiated at first evidence of CMV antigenemia. Furthermore, survival, TRM, and incidence of graft-versus-host disease (GVHD) in the CMV-seropositive cohort were evaluated and compared to a cohort of CMV-seronegative patients with a seronegative donor allografted during the same period. The aim was to determine whether and how prior CMV disease affects transplant outcome if GCV is used as preemptive therapy.

\section{Patients and methods}

A total of 115 consecutive patients, who received an HLA-identical sibling hemopoietic SCT at the Daniel den Hoed Cancer Center in Rotterdam between 1991 and 1996, were included in the study. Two groups of patients were defined: a group of 35 patients who were CMV-seronegative before transplantation and received a graft from a CMV-seronegative donor,
From the Department of Hematology, Department of Statistics, Department of Immunology, and Department of Pathology, University Hospital Rotterdam/ Daniel den Hoed Cancer Center, Groene Hilledijk 301, 3075 EA Rotterdam, The Netherlands.

Submitted May 21, 1999; accepted December 1, 1999.

Reprints: J.J. Cornelissen, Daniel den Hoed Cancer Center, Department of Hematology, Groene Hilledijk 301, 3075 EA Rotterdam, The Netherlands.
The publication costs of this article were defrayed in part by page charge payment. Therefore, and solely to indicate this fact, this article is hereby marked "advertisement" in accordance with 18 U.S.C. section 1734.

(C) 2000 by The American Society of Hematology 
hereafter designated as "CMV-seronegative patients," and a group of 80 patients in which either the donor or the patient or both were CMV-seropositive (Table 1), hereafter designated as "CMV-seropositive patients."

Patients who received a graft from an unrelated or mismatched related donor were not included in the analysis. Patients were considered "standard risk" in case of a diagnosis of acute myelogenous leukemia in first complete remission, acute lymphoblastic leukemia in first complete remission, chronic myeloid leukemia in first chronic phase, or untreated aplastic anemia. All other diagnoses were considered high risk.

\section{Transplantation}

The conditioning regimen consisted of cyclophosphamide (Cy) $(120 \mathrm{mg} / \mathrm{kg}$ of body weight) and total-body irradiation (6 Gy on each of 2 successive days with partial shielding of the lungs, for a total lung dose of $2 \times 4.5 \mathrm{~Gy}$ ). Alternatively, if patients had received locoregional irradiation before, the conditioning regimen consisted of oral busulfan $(4 \mathrm{mg} / \mathrm{kg}$ of body weight on each of 4 successive days) and Cy (120 mg/kg of body weight) (Table 1$)$. Partial T-cell depletion (TCD) was performed by sheep erythrocyte rosetting in standard-risk patients, and few high-risk patients $(n=6)$ received an unmodified graft. All patients received additional GVHD prophylaxis with cyclosporine $(3 \mathrm{mg} / \mathrm{kg}$ of body weight) from -3 days until 100 days after BMT. Cyclosporine was combined with methotrexate $\left(15 \mathrm{mg} / \mathrm{m}^{2}\right.$ on day $1 ; 10 \mathrm{mg} / \mathrm{m}^{2}$ on days 3,6 , and 11) in case of an unmanipulated graft. The source of hematopoietic stem cells was bone

Table 1. Patient characteristics

\begin{tabular}{|c|c|c|c|}
\hline & $\begin{array}{l}\text { CMV- } \\
\text { seronegative } \\
(n=35)\end{array}$ & $\begin{array}{l}\text { CMV- } \\
\text { seropositive } \\
(n=80)\end{array}$ & $\begin{array}{c}P \\
\text { Value }\end{array}$ \\
\hline Sex, male/female (n) & $20 / 15$ & $52 / 28$ & .4 \\
\hline Median age, y (range) & $37(16-54)$ & $43(18-57)$ & .02 \\
\hline \multicolumn{4}{|l|}{ Diagnosis (n) } \\
\hline $\begin{array}{l}\text { Acute myelogenous } \\
\text { leukemia }\end{array}$ & 8 & 18 & \\
\hline $\begin{array}{l}\text { Acute lymphoblastic } \\
\text { leukemia }\end{array}$ & 6 & 16 & \\
\hline Chronic myeloid leukemia & 5 & 18 & \\
\hline Non-Hodgkin's lymphoma & 8 & 7 & \\
\hline Multiple myeloma & 2 & 8 & \\
\hline Myelodysplasia & 4 & 11 & \\
\hline Aplastic anemia & 2 & 2 & \\
\hline Risk status, standard/high (n) & $13 / 22$ & $34 / 46$ & .6 \\
\hline \multicolumn{4}{|l|}{ Conditioning regimen $(\mathrm{n})$} \\
\hline Cy, TBI & 10 & 12 & \\
\hline Cy, TBI, ARA-C & 17 & 45 & \\
\hline Сy, TBI, VP16 & 5 & 16 & \\
\hline Cy, BU & 3 & 7 & \\
\hline \multicolumn{4}{|l|}{ GVHD prophylaxis (n) } \\
\hline T-cell depletion, CSA & 34 & 75 & \\
\hline CSA, MTX & 1 & 5 & \\
\hline \multicolumn{4}{|l|}{ Stem cell source $(n)$} \\
\hline BM & 32 & 73 & \\
\hline PB & 3 & 7 & \\
\hline \multicolumn{4}{|l|}{$\begin{array}{c}\text { Graft characteristics, } \\
\text { median (range) }\end{array}$} \\
\hline $\mathrm{MNC} \times 10^{8} / \mathrm{kg}$ & $0.27(0.01-0.50)$ & $0.26(0.01-1.77)$ & .8 \\
\hline CFU-GM × 104/kg & $22.3(3.0-134)$ & $24.7(2.50-79.0)$ & .96 \\
\hline T-cells $\times 10^{5} / \mathrm{kg}$ & $3.4(0.4-25)$ & $2.4(0-16)$ & .3 \\
\hline \multicolumn{4}{|l|}{ CMV serology (n) } \\
\hline $\mathrm{P}-/ \mathrm{D}-$ & 35 & - & \\
\hline $\mathrm{P}+/ \mathrm{D}-$ & - & 29 & \\
\hline $\mathrm{P}-/ \mathrm{D}+$ & - & 12 & \\
\hline $\mathrm{P}+/ \mathrm{D}+$ & - & 39 & \\
\hline
\end{tabular}

CMV indicates cytomegalovirus; Cy, cyclophosphamide; TBI, total-body irradiation; ARA-C, cytosin-arabinoside-C; VP16, etoposide; BU, busulfan; GVHD, graftversus-host disease; CSA, cyclosporine A; MTX, methotrexate; BM, bone marrow; $\mathrm{PB}$, peripheral blood; MNC, mononuclear cells; CFU-GM, granulocyte-macrophage colony-forming units; $\mathrm{P}$, patient; $\mathrm{D}$, donor. marrow in 105 patients and peripheral blood stem cells in 10 patients. The institutional review board approved the protocols, and patients provided informed consent. Graft characteristics are presented in Table 1. Acute GVHD was graded according to the Glucksberg criteria. Patients were considered evaluable for GVHD if they showed neutrophil recovery and survival beyond day 21. Patients with grades 2-4 GVHD were treated with prednisone, $1 \mathrm{mg} / \mathrm{kg}$ of body weight twice daily for 7 to 10 days, which was then tapered according to clinical response. Grade 1 GVHD was treated with topical steroids. Patients were considered evaluable for chronic GVHD if they engrafted and survived beyond day 100. Chronic GVHD was treated with the combination of cyclosporine and prednisone according to clinical response.

\section{Supportive care}

Erythrocyte and platelet blood products for transfusion were filtered to remove leukocytes and subsequently irradiated (25 Gy). All patients who were herpes simplex-seropositive before transplantation received acyclovir (200 mg, 4 times a day) until discharge. Furthermore, infection prophylaxis consisted of oral ciprofloxacin (500 mg, twice daily), oral itraconazole (200 $\mathrm{mg}$, twice daily), and intravenous penicillin during the first 14 days after BMT. Itraconazole was continued until day 90 after BMT. Prophylaxis for encapsulated bacteria and Pneumocystis carinii was prescribed for up to 6 months after BMT and consisted of cotrimoxazole ( $480 \mathrm{mg}$, once daily), which was initiated after neutrophil recovery $\left(>0.5 \times 10^{9} / \mathrm{L}\right)$ and cessation of ciprofloxacin. Patients were hospitalized in (reverse) isolation and rooms with high-efficiency particulate air-filtered air. All patients received food with a low microbial count until discharge, and parenteral alimentation was given in case of severe mucositis.

\section{Diagnostic tests for CMV reactivation and CMV disease}

The presence of CMV lower matrix protein pp65-positive leukocytes in peripheral blood or BAL fluid was analyzed as described. ${ }^{17,18}$ In short, cytospin preparations were prepared and incubated with pp65-specific monoclonal antibodies: 1 slide with clone 1C3/A-YM-1 (Biogenesis, Bournemouth, UK) and another slide with clone C10/C11 (Biotest, Seralco, Brussels, Belgium). In addition, 1 cytospin slide was used as a negative control, and slides with CMV-infected granulocytes served as positive controls. Staining was performed using the alkaline phosphataseantialkaline phosphatase method (dilution 1:50; Serotec, Oxford, UK). CMV disease was diagnosed on the basis of an inflammatory process due to CMV, confirmed either by the immediate early antigen (IEA) assay or CMV cultures, and preferably combined with the presence of typical cytopathic effects in histologic preparations if biopsies were available. All biopsies or leukocytes obtained by BAL were cultured for CMV for 14 days. Histologic examination of tissue biopsies included immunohistochemical analysis for CMV using pp65-specific monoclonal antibody clone 1C3 (Biogenesis). Pneumonia was classified as idiopathic when (multiple) biopsies of lung tissue showed interstitial inflammation but without any positive indication of viral, bacterial, parasitic, or fungal causes upon specific culture and immunohistochemical analysis.

\section{Ganciclovir therapy}

CMV-seropositive patients were monitored weekly from transplantation until day 150 for CMV antigenemia. Test results were considered positive in case of at least 1 positively staining leukocyte. Patients with a positive antigenemia test were monitored twice weekly. Preemptive GCV therapy was initiated ( $5 \mathrm{mg} / \mathrm{kg}$ of body weight intravenously, twice daily) if 4 or more positive leukocytes were identified by the IEA assay. Treatment was discontinued after 2 successive negative test results, which was considered a favorable response, if no CMV disease had developed during that time. That specific protocol of preemptive therapy was chosen to avoid GCV treatment in patients with low-grade antigenemia, who may resolve their antigenemia spontaneously, and to avoid GCV treatment in false-positive antigenemia and thereby prevent GCV-associated neutropenia while preserving effective prevention of CMV disease.

CMV disease (eg, pneumonitis and esophagitis) was treated with a combination of GCV- and CMV-specific immunoglobulins. ${ }^{5}$ Neutropenia associated with GCV therapy was defined by a neutrophil count of less than 
$0.5 \times 10^{9} / \mathrm{L}$, appearing during or shortly (less than 10 days) after GCV therapy, in patients with a neutrophil count of at least $1.0 \times 10^{9} / \mathrm{L}$ and with no other apparent cause of neutropenia.

\section{Statistical analysis}

Patients were analyzed for response of CMV reactivation to GCV treatment. Patient characteristics in the 2 cohorts were compared using Pearson's $\chi^{2}$ test or the Wilcoxon rank sum test, whichever was appropriate. All reported $P$ values are 2-sided, and a significance level of $\alpha=.05$ was used. Overall survival was measured from transplantation until death from any cause. Patients still alive at the time of analysis were censored at the last follow-up date. TRM was determined from the date of transplantation until death related to the transplantation. Patients who died from other causes were censored at the date of death. Time to acute GVHD grades 2-4 was calculated from date of transplantation until occurrence of acute GVHD. Patients who died before day 100 posttransplant without having suffered from acute GVHD were censored at the date of death. Patients without GVHD and still alive at day 100 were then censored. Time to acute GVHD grades 2-4, overall survival, and TRM were estimated by the Kaplan-Meier method. The following variables were included in the analysis of prognostic factors: sex, age, risk status, CMV serostatus of the patient/donor (both negative vs at least 1 positive), and graft characteristics (number of nucleated cells, CFU-GM [granulocyte-macrophage colony-forming units] and $\mathrm{CD}^{+} \mathrm{T}$ cells infused). Univariate survival analysis was performed using the log-rank test to see whether there was a difference in survival between the subgroups, and univariate Cox regression was used to determine whether the relation was monotonous. The variables that appeared significant in the univariate Cox regression were also used in a multivariate Cox regression. Moreover, a Cox regression analysis, with occurrence of acute GVHD grades 2-4 included as a time-dependent covariate, was performed to examine whether acute GVHD predicted for higher TRM and worse overall survival.

\section{Results}

A total of 115 consecutive HLA-identical sibling BMTs were evaluated. Patient characteristics are presented in Table 1. Two cohorts of patients are presented: a CMV-seronegative cohort and a seropositive (donor, recipient, or both) cohort. Thirty-five patients and their donors were CMV-seronegative. Eighty recipient-donor pairs were CMV-seropositive (the so-called "CMV-seropositive patients"), including 68 seropositive recipients and 51 seropositive donors. In 39 cases, both donor and recipient were seropositive. High-risk patients were distributed equally among the CMVseronegative and $\mathrm{CMV}$-seropositive cohorts, and diagnoses did also not differ between the 2 cohorts. The median age of the CMV-seropositive cohort was 43 years and exceeded that of the seronegative cohort, which was 37 years $(P=.02)$. Median numbers of mononuclear cells, CFU-GM, and T cells infused did not differ between the CMV-seronegative and CMV-seropositive cohort. Partial TCD of the graft was applied in 109 patients, and 6 patients received an unmanipulated graft because these patients suffered from high-risk disease and were considered to be at high risk for relapse. Alternatively, they received cyclosporine and methotrexate for prevention of GVHD.

\section{Ganciclovir treatment}

A total of 47 patients developed CMV antigenemia as defined by at least 1 pp65-positive peripheral blood leukocyte. Thirty of these patients showed an increase in the number of positive leukocytes up to 4 or more positive leukocytes, which was the threshold for initiating GCV treatment. Fifty-two periods of CMV antigenemia occurring in these 30 patients were treated with GCV. Two of these 30 patients were $\mathrm{CMV}$-seronegative before transplantation but received a graft from a seropositive donor. Seventeen patients developed so-called low-grade antigenemia - their IEA test results showed less than 4 positive leukocytes - and, by protocol, these patients were not treated with GCV. None of them developed CMV disease. CMV-seropositive patients with versus without CMV antigenemia did not differ with respect to their graft characteristics (mononuclear cells, CFU-GM, T cells), age, sex, underlying disease, or risk status (results not shown). Results of the 30 patients treated with GCV are presented in Table 2. Two patients died before the effects of GCV could be evaluated. The median duration of GCV treatment was 10 days (range, 2-38 days). A favorable response ( 2 consecutive negative antigenemia test results and no signs of CMV disease) was observed in 48 of 50 (96\%) evaluable treatment courses. One patient developed a CMV pneumonia that was lethal, and another patient developed a CMV esophagitis necessitating the addition of CMV-specific immunoglobulins combined with a prolonged course of GCV therapy. Recurrence of CMV antigenemia was observed 22 times in 12 patients. These recurring episodes of antigenemia all responded favorably to a second, third, fourth, or fifth course of GCV. In addition to the 2 aforementioned patients with CMV pneumonia and esophagitis, 1 other patient developed a CMV pneumonia, which was not preceded by peripheral blood CMV antigenemia. No CMV disease was observed after day 100 .

Ten patients developed GCV-related neutropenia (neutrophils less than $\left.0.5 \times 10^{9} / \mathrm{L}\right)$. The median number of neutropenic days was 10 (range, 2-36), and the median nadir was $0.255 \times 10^{9} / \mathrm{L}$ neutrophils (range, less than 5-450). Opportunistic infections during these periods of neutropenia were observed in 7 cases, including 1 case of lethal sepsis and pneumonia caused by Pseudomonas aeruginosa. Several risk factors were evaluated for their possible contributory role to GCV-related neutropenia. Graft characteristics were not associated with neutropenia. An elevated bilirubin level, but not impaired kidney function, at the onset of GCV therapy strongly correlated with the appearance of GCVrelated neutropenia $(P=.03)$.

\section{Survival, TRM, and GVHD}

Overall survival of these 115 patients was $64 \% \pm 4 \%$ at 1 year and $47 \% \pm 5 \%$ at 5 years posttransplant. The median follow-up for patients still alive was 43 months (range, 9-95 months). Survival was not significantly affected by diagnosis, risk status, sex, and graft characteristics (such as numbers of CFU-GM, T cells, and mononuclear cells infused). In univariate analysis, both positive CMV serology (of donor or recipient) and older age predicted for inferior survival. However, only CMV serology significantly affected survival $(P=.03)$ in multivariate Cox regression analysis.

Table 2. Treatment results

\begin{tabular}{lcccc}
\hline $\begin{array}{c}\text { Number } \\
\text { of cycle of } \\
\text { ganciclovir } \\
\text { therapy }\end{array}$ & $\begin{array}{c}\text { No. of } \\
\text { patients }\end{array}$ & Response & Relapse & $\begin{array}{c}\text { No. of } \\
\text { patients with } \\
\text { cytomegalovirus } \\
\text { disease; site }\end{array}$ \\
\hline 1 & 30 & $27 / 29$ & 12 & 2 (1 pneumonia; \\
1 esophagitis) \\
2 & 12 & $12 / 12$ & 6 & - \\
3 & 6 & $6 / 6$ & 3 & - \\
4 & 3 & $2 / 2$ & 1 & - \\
5 & 1 & $1 / 1$ & - & 2 \\
\hline
\end{tabular}

Fifty of 52 treatment courses were evaluable for response. 
The seropositive cohort included also 12 "-/+" patients-those who were seronegative before SCT but received a graft from a positive donor. Overall survival was $45 \% \pm 9 \%$ in these 12 patients at 36 months after SCT, which did not differ from $39+/+$ patients and $29+/$ - patients, who completed the CMV-seropositive cohort (Table 1). In contrast, overall survival was $70 \% \pm 8 \%$ in the seronegative group at 36 months after SCT (Figure 1).

Excess mortality in the CMV-seropositive cohort (Figure 1) was not due to relapse but appeared to be due to increased TRM. The variables age, CMV serology, diagnosis, risk status, sex, and graft characteristic were also evaluated for a possible association with TRM. Of these, only positive CMV serology significantly predicted for increased TRM $(P=.03)$. TRM was $35 \% \pm 5 \%$ for all 115 patients at 5 years posttransplant and $18 \% \pm 7 \%$ versus $42 \% \pm 6 \%$, respectively, for CMV-seronegative and CMVseropositive patients (Figure 2$)(P=.03)$. In contrast, these figures were $30 \% \pm 6 \%$ and $40 \% \pm 8 \%$ for younger and older patients, which was not statistically significant $(P=.5)$. We also evaluated whether CMV antigenemia would quantitatively predict for increased TRM. The median number of IEA-positive leukocytes was 10 (range, 4-130). A trend toward a higher TRM was observed for patients with more than 10 positive leukocytes as compared to patients below that median number: TRM was $46 \% \pm 14 \%$ versus $29 \% \pm 12 \%$, respectively, which was not significant. In addition, when evaluated as a continuous variable, the IEA number yielded a hazard ratio of more than 1 but remained not significant. Specific causes of death are presented in Table 3. Excess mortality in the CMV-seropositive cohort included pneumonia/adult respiratory distress syndrome $(n=12)$, idiopathic pneumonitis $(n=9)$, GVHD $(\mathrm{n}=3)$, and CMV $(\mathrm{n}=2)$. All patients with lethal idiopathic pneumonitis were evaluated by BAL and subsequent IEA analysis as well as viral cultures. Test results were CMV-negative in 8 and confirmed by further histologic evaluation of biopsies in 7 of these 8 patients. One patient with peripheral blood CMV antigenemia showed IEA-positive leukocytes in her BAL. A diagnosis of CMV pneumonia was, however, rejected, because cultures as well as IEA staining of an open lung biopsy (performed 2 days later) were found negative and histology did not show the typical histologic features associated with CMV. Apart from these 9 lethal cases of idiopathic pneumonitis, 6 other patients also developed pneumonitis,

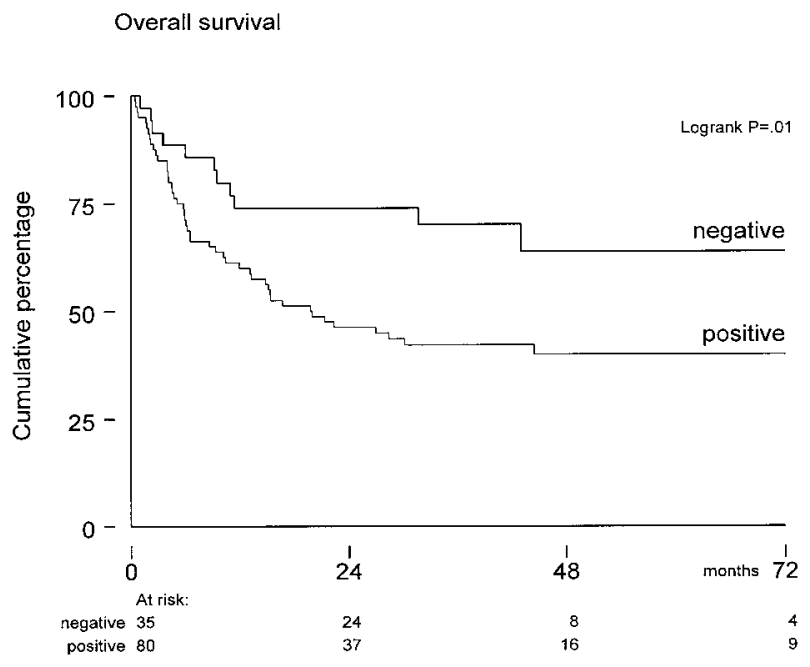

Figure 1. Overall survival from transplantation in CMV-seronegative patients $(n=35)$ versus CMV-seropositive patients (donor or recipient CMV-seropositive) $(\mathbf{n}=\mathbf{8 0})$. Median follow-up was 43 months. The survival difference was significant $(P=.01)$ by log-rank analysis.
Transplant related mortality

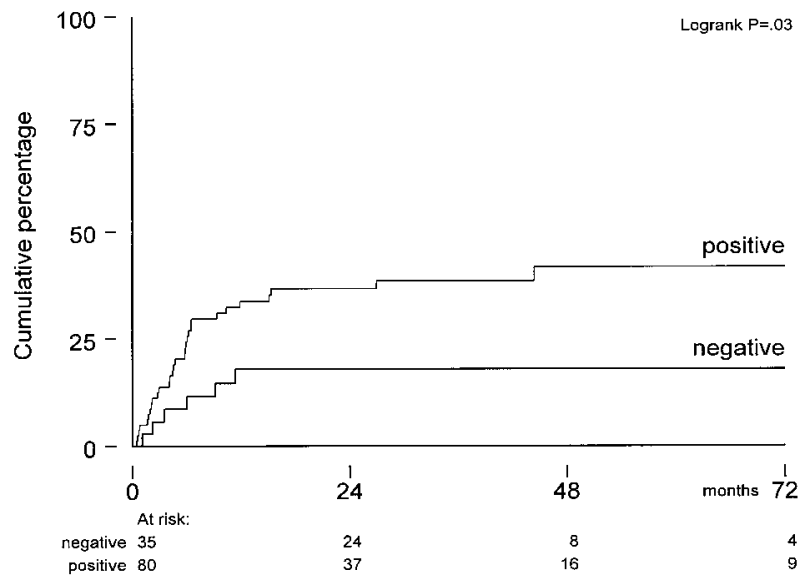

Figure 2. Probabilities of developing transplant-related mortality in CMVseropositive patients $(n=80)$ versus CMV-seronegative patients $(n=35)$. $P=.03$ by log-rank analysis.

which was considered idiopathic after thorough evaluation. Corticosteroid treatment resulted in a favorable response in all of them.

The actuarial probability of developing acute GVHD grades 2-4 was $33 \% \pm 4 \%$ by 100 days posttransplant. A higher incidence of acute GVHD grades 2-4 was observed in CMV-seropositive patients (42\% versus $14 \%, P=.01$; Figure 3 ). Again, several risk factors were evaluated for a possible association with the probability of developing acute GVHD. Both univariate and multivariate analysis showed that positive CMV serology remained an independent risk factor (Figure 3 ). In addition, the number of $\mathrm{CD}^{+} \mathrm{T}$ cells in the graft was also associated with increased acute GVHD grades 2-4 $(P=.01)$. Following the observation of more GVHD and enhanced TRM in CMV-seropositive patients, we subsequently analyzed whether patients suffering from acute GVHD would develop an increased risk for TRM and reduced overall survival. Cox regression analysis was performed using acute GVHD grades 2-4 as a time-dependent covariate and TRM and overall survival as endpoints. Hazard ratios for overall survival and TRM were 2.0

Table 3. Relapse mortality and treatment-related mortality

\begin{tabular}{|c|c|c|}
\hline & $\begin{array}{c}\text { CMV- } \\
\text { seronegative } \\
(n=35)\end{array}$ & $\begin{array}{l}\text { CMV- } \\
\text { seropositive } \\
(\mathrm{n}=80)\end{array}$ \\
\hline Relapse & 5 & 17 \\
\hline Treatment-related mortality & 6 & 30 \\
\hline \multicolumn{3}{|l|}{ Specific causes } \\
\hline CMV disease & - & 2 \\
\hline GVHD & 1 & 3 \\
\hline Interstitial pneumonitis & 3 & 9 \\
\hline \multicolumn{3}{|l|}{ Pneumonia } \\
\hline Aspergillus fumigatus & - & 1 \\
\hline $\begin{array}{l}\text { Streptococcus } \\
\text { pneumoniae }\end{array}$ & - & 1 \\
\hline Pneumocystis carinii & - & 2 \\
\hline $\mathrm{ECl}$ & - & 2 \\
\hline ARDS/sepsis & - & 6 \\
\hline VOD/HUS & - & 3 \\
\hline EBV-LPD & 1 & - \\
\hline Hemorrhage & 1 & 1 \\
\hline
\end{tabular}

CMV indicates cytomegalovirus; GVHD, graft-versus-host disease; $\mathrm{ECI}$, e causa ignota; ARDS, adult respiratory distress syndrome; VOD, veno-occlusive disease; HUS, hemolytic uremic syndrome; EBV-LPD, Epstein-Barr virus-lymphoproliferative disease. 
Acute GVHD grades II-IV

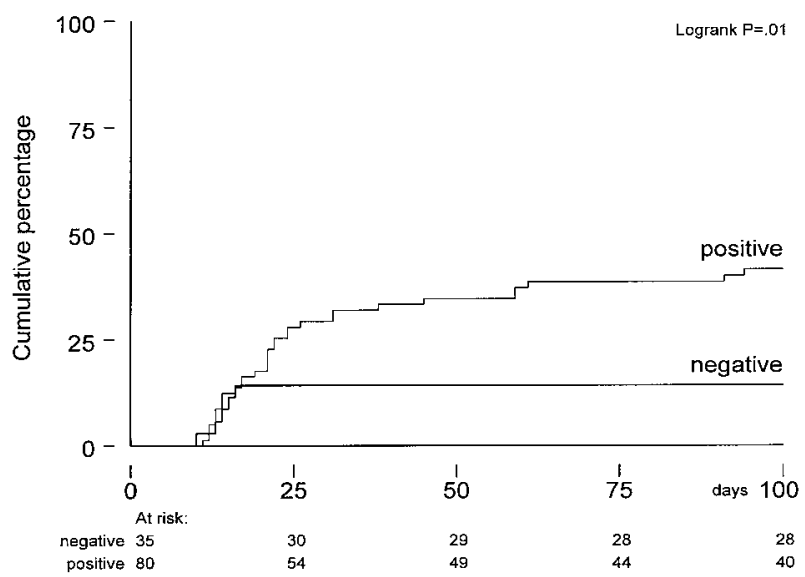

Figure 3. Time to acute GVHD grades $2-4$ in CMV-seropositive patients $(n=80)$ versus CMV-seronegative patients $(n=35)$ calculated from date of transplantation expressed by Kaplan-Meier curves. $P=.01$ by log-rank analysis.

(95\% confidence interval $[\mathrm{CI}], 1.2-3.4 ; P=.01)$ and $2.5(95 \% \mathrm{CI}$, 1.3-4.8; $P=.007)$, respectively, which remained significant in multivariate analyses. Fifteen patients developed limited chronic GVHD, and 9 patients were treated for extensive chronic GVHD. The probability of developing limited or extensive chronic GVHD was $23 \% \pm 8 \%$ at 12 months after SCT in CMV-seronegative patients and $27 \% \pm 6 \%$ in the seropositive group; the difference appeared insignificant.

\section{Discussion}

In this study, we show that CMV seropositivity continues to represent a major adverse risk factor for transplant-related morbidity and mortality despite the very efficient prevention of CMV disease by preemptive GCV therapy in patients receiving a partial TCD graft. Increased TRM accounted for inferior survival observed in CMV-seropositive patients versus CMV-seronegative patients. Furthermore, an increased incidence of acute GVHD was observed in CMV-seropositive patients, and the development of acute GVHD strongly predicted for TRM and overall survival. Thus, CMV disease prior to transplantation does not affect transplantation outcome by CMV disease itself but, rather, by increasing the incidence of acute GVHD.

Prerequisites for preemptive therapy are sensitive and specific methods for early diagnosis, such as the CMV antigenemia test, as well as the ability to identify patients at risk. Several risk factors have been identified, including pretransplant serostatus, GVHD, and TCD of the graft. ${ }^{1,2,14-16}$ The CMV-seropositive patients presented in our study can be considered at high risk for CMV disease because of these risk factors and the relative high percentage of older patients with advanced disease. Our CMV-seropositive donor-recipient pairs were monitored weekly for CMV antigenemia, which permitted an early detection and early institution of GCV treatment. The approach resulted in an almost complete prevention of CMV disease in this cohort of patients who were at high risk for CMV infection and disease. Our results compare well to earlier findings with respect to prevention of CMV disease by preemptive GCV. ${ }^{9-16}$

GCV may effectively prevent CMV disease if given prophylactically or as preemptive therapy. ${ }^{7-16}$ Preemptive therapy for a short time is to be preferred because continued GCV prophylaxis is frequently associated with neutropenia and opportunistic infec- tions, which then may offset the beneficial effects of GCV. ${ }^{7-9}$ Our approach of a limited course of preemptive therapy did not prevent the occurrence of GCV-associated neutropenia. Ten of 30 patients receiving 1 or more cycles of GCV therapy developed severe neutropenia, which was complicated by opportunistic infections in 7 patients. The probability of developing neutropenia did not correlate with renal function, low graft cellularity, or numbers of CFU-GM in the graft. However, hyperbilirubinemia at the start of GCV therapy was significantly associated with neutropenia, which compares well to findings recently reported by Salzberger et al. ${ }^{19}$

Studies evaluating preemptive GCV therapy in HLA-identical sibling BMT also suggested that TRM in CMV-seropositive patients can be reduced to what can be achieved in CMVseronegative patients, although no formal comparison has been reported so far. Our results indicate that survival remains inferior in these patients as compared to transplants in seronegative pairs. Reduced survival was predominantly due to increased infectious mortality, which was not caused by CMV itself (Table 3). Relapse mortality was not different among the 2 cohorts of patients, but TRM accounted for the observed survival difference. GCVassociated neutropenia contributed to TRM, but the latter effect did not explain the difference of survival among seropositive and seronegative patients.

If not by CMV disease itself, nor by the adverse effects of the drug needed for prevention, how does CMV affect transplant outcome so strongly? Increased susceptibility for opportunistic infections and subsequent TRM may come from an enhanced incidence of GVHD. We observed a significantly higher incidence of acute GVHD in CMV-seropositive patients, which could not be explained by other risk factors, such as age, risk status, or number of T cells in the graft. How do CMV and GVHD relate? Established GVHD is immunosuppressive itself, and the immunosuppressive drugs needed to treat GVHD add even more suppression. Conversely, CMV may also play a role in the development of GVHD. Several studies have shown an association between pretransplant seropositivity and the probability of developing GVHD after transplantation. ${ }^{20-25}$ Experimentally, murine CMV infection enhanced the ability of parental spleen cells to induce GVHD. ${ }^{26}$ In addition, latent human CMV can be detected in most organs, including the liver, the spleen, and the endothelium. ${ }^{27} \mathrm{CMV}$ infected endothelial cells have been shown to produce inflammatory cytokines such as interleukin-6, resulting in leukocyte adhesion, which may play a role in the initial phases of initiating a graft-versus-host reaction. ${ }^{28}$ Lichtman et al have shown that interleukins such as interleukin-1, tumor necrosis factor, and interleukin-6 play a pivotal role in the initial phase of T-cell activation before $\mathrm{T}$ cells are specifically activated by recipient allo-antigens. ${ }^{29}$ The inflammatory response evoked by CMV in recipient endothelium could thereby contribute to the initiation of GVHD. We evaluated whether the appearance of acute GVHD would predict for enhanced TRM by using GVHD as a timedependent covariate in a Cox regression analysis. It was shown that development of acute GVHD at that time significantly increased the risk for both higher TRM and reduced overall survival. These findings indicate that the adverse effects of CMV seropositivity are mediated via an enhanced incidence of acute GVHD and subsequent increased TRM.

Our results were observed in patients receiving a stem cell graft that was partially depleted of T cells. That particular mode of graft manipulation may, on one hand, reduce the ability to mount an immune response toward CMV and, on the other hand, may still be associated with acute GVHD, which may contribute to TRM in 
CMV-seropositive patients. Most of our patients received more than $10^{5} \mathrm{CD} 3 \mathrm{~T}$ cells per kilogram of body weight, which seems to be the threshold for acute GVHD. ${ }^{30}$ The incidence of chronic GVHD was, however, significantly less compared with unmanipulated SCT, and no late CMV disease was observed, which may be one of the opportunistic infections associated with chronic GVHD. It remains to be established whether the reduction of chronic GVHD outweighs an adverse effect on TRM in CMV-seropositive patients who receive a stem cell graft that is partially depleted of T cells. Preferably, a comparative study should answer that question.

In conclusion, CMV serostatus before HLA-matched allogeneic TCD sibling SCT remains an independent adverse risk factor despite efficacious prevention of CMV disease by preemptive GCV therapy. Additional approaches are needed to prevent CMV reactivation and antigenemia following allogeneic TCD sibling SCT. First, GCV prophylaxis instead of preemptive therapy may more effectively control CMV infection. Second, apart from prolonged high-dose acyclovir, ${ }^{9,31}$ new antiviral drugs such as cidofovir and benzimidavir might prove to inhibit the virus more potently. ${ }^{32}$ Third, adoptive CMV-specific immunotherapy might prove beneficial in CMV-seropositive patients. ${ }^{33-35}$ Reconstitution of CD8 CMV-specific T cells have been shown to be decisive for control of CMV after BMT. ${ }^{36}$ Supplementation of such T cells after transplantation, especially in the setting of TCD transplantation, should be further explored for control of CMV reactivation and its associated complications.

\section{References}

1. Meyers JD, Flournoy N, Thomas E. Risk factors for cytomegalovirus infection after human bone marrow transplantation. J Infect Dis. 1986;153: 478

2. Zaia JA. Cytomegalovirus infection. In: Forman SJ, Blume KG, Thomas ES, eds. Bone Marrow Transplantation. Boston, MA: Blackwell Scientific Publications; 1994:376.

3. Meyers JD, Ljungman P, Fisher LD. Cytomegalovirus excretion as a predictor of cytomegalovirus disease after marrow transplantation: importance of cytomegalovirus viremia. J Infect Dis. 1990; 162:373.

4. Emanuel E, Cunningham I, Jules-Elysee K, et al. Cytomegalovirus pneumonia after bone marrow transplantation successfully treated with the combination of ganciclovir and high-dose intravenous immune globulin. Ann Intern Med. 1988;109:777.

5. Ljungman $P$, Engelhard D, Link $\mathrm{H}$, et al. Treatment of interstitial pneumonitis due to cytomegalovirus with ganciclovir and intravenous immune globulin: experience of the European Bone Marrow Transplant Group. Clin Infect Dis. 1992;14: 831.

6. Reed EC, Bowden RA, Dandliker PA, Lilleby KE, Meyers JD. Treatment of cytomegalovirus pneumonia with ganciclovir and intravenous cytomegalovirus immunoglobulin in patients with bone marrow transplants. Ann Intern Med. 1988; 109:783.

7. Winston DJ, Ho WG, Bartoni K, et al. Ganciclovir prophylaxis of cytomegalovirus infection and disease in allogeneic bone marrow transplant recipients. Ann Intern Med. 1993;118:179.

8. Goodrich JM, Bowden RA, Fisher L, Keller C, Schock G, Meyers JD. Ganciclovir prophylaxis to prevent cytomegalovirus disease after allogeneic marrow transplant. Ann Intern Med. 1993;118 173.

9. Prentice HG, Kho P. Clinical strategies for the management of cytomegalovirus infection and disease in allogeneic bone marrow transplant. Bone Marrow Transplant. 1997;19:135

10. Schmidt GM, Horak DA, Niland JC, Duncan SR Forman SJ, Zaia JA. A randomized, controlled trial of prophylactic ganciclovir for cytomegalovirus pulmonary infection in recipients of allogeneic bone marrow transplants. N Engl J Med. 1991; 324:1005.

11. Goodrich JM, Mori M, Gleaves CA, et al. Early treatment with ganciclovir to prevent cytomegalovirus disease after allogeneic bone marrow transplantation. N Engl J Med. 1991;325:1601.

12. Boeckh M, Gooley TH, Myerson D, Cunningham T, Schoch G, Bowden RA. Cytomegalovirus pp65 antigenemia-guided early treatment with ganciclovir versus ganciclovir at engraftment after allogeneic marrow transplantation: a randomized double-blind study. Blood. 1996;88:4063.
13. Einsele $\mathrm{H}$, Ehninger $\mathrm{H}$, Hebart $\mathrm{H}$, et al. Polymerase chain reaction monitoring reduces the incidence of cytomegalovirus disease and the duration and side effects of antiviral therapy after bone marrow transplantation. Blood. 1995;86:2815.

14. Verdonck LF, Dekker AW, Rozenberg-Arska M, Van den Hoek MR. A risk-adapted approach with a short course of ganciclovir to prevent cytomegalovirus (CMV) pneumonia in CMV-seropositive recipients of allogeneic bone marrow transplants. Clin Infect Dis. 1997;24:901.

15. Bacigalupo A, Tedone E, Soracco M, et al. CMVantigenemia after allogeneic bone marrow transplantation: correlation of CMV antigen positive cell numbers with transplant related mortality. Bone Marrow Transplant. 1995;16:155.

16. Bacigalupo A, Tedone E, Sanna MA, et al. CMV infections following allogeneic BMT: risk factors, early treatment and correlation with transplan related mortality. Hematologica. 1997;77:507.

17. Van der Bij W, Torensma R, Van Son WJ, et al. Rapid immunodiagnosis of active cytomegalovirus infection by monoclonal antibody staining of blood leukocytes. J Med Virol. 1988;25:179.

18. Kuenen-Boumeester V, Van Loenen P, De Bruijn EMCA, Henzen-Logmans SC. Quality control of immunocytochemical staining of efflusions using a standardized method of cell processing. Acta Cytol. 1996;40:475

19. Salzberger B, Bowden RA, Hackman RC, Davis Ch, Boeckh M. Neutropenia in allogeneic marrow transplant recipients receiving ganciclovir for prevention of cytomegalovirus disease: risk factors and outcome. Blood. 1997;90:2502.

20. Boström L, Ringden O, Sundberg B, Linde A, Tonnemar J, Nilsson B. Pre-transplant herpes virus serology and graft-versus-host disease. Transplantation. 1988;46:548.

21. Boström L, Ringden O, Gratama JW, Jacobsen N, Zawwn F, Nilsson B, for the Leukaemia Work ing Party of the European Group for Bone Marrow Transplantation. The impact of pre-transplant herpes virus serology on acute and chronic graftversus-host disease. Transplant Proc. 1990;22: 206.

22. Lönnqvist B, Ringden O, Wahren B, Gahrton G, Lundgren G. Cytomegalovirus infection associated with and preceding chronic graft-versus-host disease. Transplantation. 1984;38:465.

23. Jacobsen N, Anderson HK, Skinhoj P, et al. Correlation between donor $\mathrm{CMV}$ immunity and chronic GVHD after allogeneic bone marrow transplantation. Scand J Haematol. 1986;36:499.

24. Gratama JW, Fibbe WE, Naipal AMIH, et al. Cytomegalovirus immunity and T-lymphocytes in bone marrow donors and acute GVHD. Bone Marrow Transplant. 1986;1:141
25. Gratama JW, Zwaan FE, Stijnen T, et al. Herpes virus immunity and acute graft-versus-host disease. Lancet. 1987;1:471.

26. Grundy JE, Shanley JE, Shearer GM. Augmentation of graft-versus-host reaction by cytomegalovirus infection resulting in interstitial pneumonitis. Transplantation. 1985;39:548.

27. Hendrikx MGS, Beuken E, Slobbe RL, Brugge man CA. Detection and sequence analysis of the major immediate early and PP150 gene of latent human cytomegalovirus in spleen, liver and kidney tissues of trauma victims. J Med Virol. 1996; 50:193.

28. Grefte A, Van der Giessen M, Van Son W, The $\mathrm{TH}$. Circulating cytomegalovirus (CMV)-infected endothelial cells in patients with an active CMV infection. J Infect Dis. 1993;167:270.

29. Lichtman A, Krenger W, Ferrara JLM. Cytokine networks. In: Ferrara JLM, Deeg HJ, Burakoff SJ, eds. Graft-versus-Host Disease. New York, NY: M. Dekker; 1997.

30. Verdonck LF, Dekker AW, De Gast GC, van Kempen ML, Lokhorst HM, Nieuwenhuis HK. Allogeneic bone marrow transplantation with a fixed low number of T-cells in the marrow graft. Blood. 1994;83:3090.

31. Prentice HG, Gluckman E, Powles RP, et al. The impact of long-term acyclovir on cytomegalovirus infection and survival in allogeneic bone marrow transplantation. Lancet. 1994;343:749.

32. Hebart H, Kanz L, Jahn G, Einsele H. Management of cytomegalovirus infection after solid-organ or stem cell transplantation. Drugs. 1998; $55: 59$

33. Greenberg PD, Reusser P, Goodrich JM, Riddel SR. Development of a treatment regimen for human cytomegalovirus (CMV) infection in bone marrow transplantation recipients by adoptive transfer of donor-derived CMV-specific T-cell clones expanded in vitro. Ann N Y Acad Sci. 1991;636:184.

34. Riddell SR, Watanabe KS, Goodrich JM, Li CR, Agha ME, Greenberg PD. Restoration of viral immunity in immunodeficient humans by the adoptive transfer of T-cell. Science. 1992;257:238.

35. Walter EA, Greenberg PD, Gilbert MJ, et al. Reconstitution of cellular immunity against cytomegalovirus in recipients of allogeneic bone marrow by transfer of T-cell clones from the donor. $\mathrm{N}$ Engl J Med. 1995;333:1038.

36. Reusser P, Riddell SR, Meyers JD, Greenberg PD. Cytotoxic T-lymphocyte response to cytomegalovirus after human allogeneic bone marrow transplantation: pattern of recovery and correlation with cytomegalovirus infection and disease. Blood. 1991;78:1373. 